\title{
Desafios do ensino superior brasileiro em tempos de pandemia da COVID-19: repensando a prática docente
}

\author{
Challenges of Brazilian higher education in times of COVID-19 \\ pandemic: rethinking teaching practice
}

\author{
Alan Silus a, b (D) \\ Angelita Leal de Castro Fonseca ${ }^{b}$ (i) \\ Djanires Lageano Neto de Jesus ${ }^{a, *}$ (i)
}

\begin{abstract}
RESUMO: A pandemia da COVID-19 parou o mundo e várias medidas para erradicar o contágio foram adotadas, uma delas é o isolamento social, com restrições e fechamento provisório de escolas e universidades, no Brasil, de acordo com a Lei $n^{\circ} 13.979$, de 06 de fevereiro de 2020 e Portaria MEC $n^{\mathrm{a}} 343$, de 17 março de 2020. O modo de ensinar e aprender cedeu espaço exclusivo a remotividade do ensino, com a utilização das TDIC's e emergentemente professores e estudantes tiveram que se adaptar abruptamente. Nesse sentido, o objetivo deste artigo é apresentar os desafios didático-pedagógicos da prática docente do ensino superior brasileiro em tempos de pandemia. Como metodologia, trata-se de uma abordagem qualiquantitativa, descritiva, bibliográfica, documental e exploratória, buscando ancorar nas teorias clássicas e contemporâneas da educação. Os resultados, baseados nas 442 pessoas entrevistadas, no período de 01 a 25 de julho de 2020, apontam desafios impostos aos professores nativos do ensino presencial e que enfrentam a adaptabilidade do uso das tecnologias educacionais, para fomentar discussões e alternativas híbridas de ensino e aprendizagem.
\end{abstract}

Palavras-chave: Ensino Remoto Emergencial; Educação Superior; Tecnologias.

ABSTRACT: The COVID-19 pandemic stopped the world and several measures to eradicate contagion are adopted, one of which is social isolation, with restrictions and provisional closure of schools and universities in Brazil, in accordance with Law 13,979, of February 6, 2020 and Ordinance MEC. 343, of March 17, 2020. The COVID-19 pandemic stopped the world, and several measures were taken to eradicate contagion, one of which is social isolation, with restrictions and provisional closure of schools and universities, according to Law 13,979, of February 6, 2020. The way of teaching and learning gave way to the remotivity of teaching with the use of TDIC's and the emergency is due to the abrupt adaptation of teachers and students. In this sense, the objective of this article is to present the didactic-pedagogical challenges of teaching practice in Brazilian higher education in times of pandemic. As a methodology, it is a qualitative, quantitative, descriptive, bibliographic, documentary and exploratory approach, seeking to anchor in classic and contemporary theories of education. The results, based on the 442 people interviewed, in the period from 01 to 25 July 2020, point to challenges imposed on native teachers of classroom teaching and who face the adaptability of the use of educational technologies to foster discussions and hybrid teaching and learning alternatives.

Keywords: Emergency Remote Education; College Education; Technologies.

a Grupo de Pesquisa Educação, Cultura e Diversidade, Universidade Estadual de Mato Grosso do Sul, Campo Grande, MS, Brasil.

b Centro Universitário UNIGRAN Capital, Campo Grande, MS, Brasil.

* Correspondência para/Correspondence to: Djanires Lageano Neto de Jesus. Endereço Institucional: Universidade Estadual de Mato Grosso do Sul (UEMS) - Av. Dom Antônio Barbosa, 4155 - Vila Santo Amaro, Campo Grande - MS, Campo Grande-MS, Brasil. E-mail: netoms@uems.br.

Recebido em/Received: 08/09/2020; Aprovado em/Approved: 20/11/2020.

Artigo publicado em acesso aberto sob licença CC BY 4.0 Internacional $@(1)$ 


\section{INTRODUÇÃO}

Recentemente o mundo parou em função da pandemia da COVID-19 e os casos da doença provocada pelo novo coronavírus são crescentes. O consenso mundial de acordo com os órgãos oficiais de saúde é o isolamento social, com restrições de viagens, fechamento provisório de escolas, universidades e comércios em geral. Segundo dados da Organização das Nações Unidas para a Educação, a Ciência e a Cultura (UNESCO, 2020), mais de 1,5 bilhão de estudantes de 191 países estão sendo afetados pelo fechamento das escolas e universidades.

Diante da necessidade emergencial de fechamento das instituições de ensino, muitos desafios para a continuidade da educação mundial surgiram, dentre eles: harmozição do relacionamento entre estudantes e professores; o uso excessivo da tecnologia como ferramenta de comunicação para o ensino e aprendizagem; a dificuldade de professores e estudantes com o uso das Tecnologias Digitais de Informação e Comunicação (TDIC's); além de todas as questões socioemocionais que envolvem docentes, discentes, famílias e sociedade.

Com a necessidade de implementar os meios digitais, conforme as orientações da Portaria do Ministério da Educação (MEC) n 343 de 18 de Março de 2020 que, posteriormente foi alterada pela Portaria $\mathrm{n}^{\circ}$ 345, publicada em 19 de março de 2020 e no dia 17 de junho de 2020 consolidado pela Portaria $n^{\circ}$ 544, as Instituições de Ensino Superior (IES) da modalidade presencial, passaram a realizar o Ensino Remoto Emergencial (ERE). Importante destacar que o ERE não segue as diretrizes da Educação a Distância (EAD), que possui larga experiência e normativas próprias. Dessa forma, a remotividade do ensino presencial se justifica pela utilização das TDIC's e a emergência se deve a total adaptação em muitos casos abruptamente para os recursos tecnológicos.

O fato de se observar como as IES estão reagindo a este problema do ERE, sobretudo na ineficiência e despreparo em prover a formação continuada ao uso das tecnologias educacionais, que nada tem a ver com a educação a distância (EAD), a intenção é buscar um estudo sobre a seguinte problemática: Quais contribuições na práxis docente da educação superior brasileira presencial, podem emergir do ERE, sobretudo nos aspectos didáticos pedagógicos?

$\mathrm{Na}$ busca de responder esse questionamento, o objetivo geral da pesquisa que está em andamento é refletir sobre a práxis docente da educação superior brasileira presencial em seus aspectos didático-pedagógicos e socioemocionais com o ERE. Como recorte para o presente artigo, apresentamos inicialmente os desafios da prática docente do ensino superior brasileiro em tempos de pandemia da COVID-19.

Hipoteticamente muitas respostas podem eclodir com a reflexão científica, como: perceber que o processo de adaptação metodológica teve por consequência o direcionamento a um novo olhar para a profissão docente; repensar e reorganizar o trabalho pedagógico, incluindo aspectos que vão além do ensinar e aprender; identificar a necessidade de capacitação continuada em tecnologias digitais por parte das IES; e reconhecer que as questões socioemocionais do docente são cruciais para a qualidade do ensino e aprendizagem dos estudantes.

De maneira emergencial, professores e gestores educacionais tiveram que adaptar em tempo real a situação das Instituições de ensino, incluindo seus planos de atividades, metodologias e conteúdos de forma geral, passando ainda da modalidade presencial para o ERE, totalmente experimental. Esse novo olhar tenciona à prática docente novas intercorrências cotidianas e, promove um novo olhar para a formação de 
professores, tornando predominantes novas formas de garantir a eficácia, a qualidade da ação e produções sociais que envolvem o processo educativo (CHARLOT, 2013).

Nesse sentido, organizamos este texto em três momentos: um primeiro para contextualizar as práticas educativas em tempo de crise, de forma a refletir sobre as novas estratégias e abordagens de aprendizagem. $O$ segundo momento apresentamos a ação da tecnologia na prática docente bem como as habilidades necessárias para enfrentar os desafios das salas virtuais, incluindo algumas práticas exitosas; por fim, no percurso metodológico, foram apresentados os resultados parciais da pesquisa nacional que coadunam com os objetivos de apresentar os desafios didáticopedagógicos da prática docente do ensino superior brasileiro na pandemia.

\section{O ENSINO SUPERIOR E AS TRANSFORMAÇÕES FRENTE À COVID-19}

A pandemia da COVID-19 modificou a vida do homem silenciando cidades, fechando instituições das mais diversas atividades, inclusive as educacionais. Para conter 0 avanço das contaminações do vírus, medidas brasileiras foram tomadas e o isolamento social foi necessário, de acordo com a Lei $\mathrm{n}^{\circ} 13.979$, de 06 de fevereiro de 2020, que estabelece as medidas para o enfrentamento da emergência em saúde pública de importância internacional decorrente da doença por coronavírus e, posteriormente, com a publicação da Portaria MEC $n^{a}$ 343, de 17 março de 2020 (BRASIL, 2020a; 2020b). $E$ com isso emergiram questões primordiais que mobilizaram educadores e pesquisadores pelo mundo, tais como: as escolas e universidades estavam preparadas para implementação de TDIC's? Os professores estavam preparados para ensinar por meio das tecnologias? Os estudantes além do acesso a internet, possuíam habilidades para aprender por meio da TDIC's? As práticas pedagógicas docentes utilizadas na modalidade presencial, poderiam continuar da mesma forma no ensino remoto? Tais questionamentos contextualizam as diferentes transformações provocadas especialmente no ensino superior, que a nossa pesquisa em andamento busca discutir.

A adaptação das IES para a modalidade remota, passou então a ser chamada de Ensino Remoto Emergencial (ERE) que segundo Holges et al. (2020) é a mudança temporária da entrega de instrução (ensino) para um modo de entrega alternativo devido a circunstância de crise, não sendo o mesmo da Educação a Distância (EAD), pois este, tem normativas próprias e sistemas de ensino e aprendizagem que em muitos casos divergem do ensino presencial. Desta forma o objetivo do ERE, não é criar um ambiente robusto para o ensino on-line, mas sim fornecer soluções de ensino totalmente remotas, que seriam ministradas presencialmente e temporariamente serão ofertadas de maneira on-line.

A necessidade de implementação do ERE, chamou atenção das IES para a fragilidade das implementações das TDIC's, na modalidade presencial. As TDIC's de acordo com Antunes et al. (2020) tem se mostrado em crescimento global, direcionando as IES a reformular além de suas práticas pedagógicas, suas ferramentas tecnológicas de ensino, construindo programas, redes e mídias que permitam a integração dos estudantes com professores em redes de aprendizagem em Ambientes Virtuais de Aprendizagem (AVA), dando continuidade do sistema utilizado pelo ensino superior, mesmo no isolamento social.

As TDIC's além de possibilitar a imersão dos estudantes e professores no ensino elearning (ensino eletrônico apoiado em tecnologias digitais), também introduz seus participantes (praticantes do uso) ao chamado letramento digital, que de acordo com Suguimoto et al. (2017) é definido como o conjunto de conhecimentos e habilidades 
necessárias para atuar com dispositivos eletrônicos, incluindo a compreensão de alguns comandos, tais como: salvar e enviar um documento via rede, além do entendimento de algumas interfaces de computadores e dispositivos móveis.

Com a implementação abrupta para o ERE, muitos estudantes e professores não estavam preparados e possuíam baixo letramento digital. Desta maneira, o letramento digital exige constantes atualizações, pois há uma mudança constante das ferramentas digitais e a capacidade de adaptação às tecnologias digitais passou a ser uma habilidade decisiva para a inclusão social atual.

O ERE trouxe então à tona, o quão deficitário é o sistema de ensino superior, no que se refere a implementação das TDIC's e do letramento e cultura digital nos cursos de graduação. Para Oliveira et al. (2020) é necessária a implementação de estudos que investiguem a prática dos educadores com a utilização das TDIC's, visando uma formação superior que desenvolva nos estudantes, compreensão do letramento digital e novas formas de ensino que potencializam a aprendizagem, estabelecendo novas dimensões de comunicação e interação. Contudo, para que esta premissa ocorra é necessário anteriormente que as IES, promovam atividades de formação continuada docente, estas que darão suporte às transformações e inovações pedagógicas tecnológicas no meio remoto.

De acordo com Masetto (2002) inovar no trabalho educativo requer dos docentes, uma análise criteriosa sobre o sentido de ensinar, buscando analisar todo o seu processo frente aos estudantes, aos quais podem se refletir os seguintes aspectos: busca por novas metodologias especialmente as que estimulem a atividade dos estudantes no seu processo de ensino; a aproximação humanizada aos estudantes, na busca por influenciar e motivá-los ao aprendizado; o uso de tecnologias educacionais; a reformulação das avaliações; e por fim o permanente compromisso de formação continuada docente.

Para Márquez et al. (2018) a universidade é um agente facilitador de competências profissionais, estas que estão diretamente ligadas ao favorecimento das habilidades em tecnologias digitais e aos processos de ensino e aprendizagem, em que os docentes são os mediadores, facilitadores e motivadores, para uma aprendizagem significativa, crítica e autônoma. Desta forma, é importante a formação docente e as competências didáticas frente às TDIC's, as quais devem estar ligadas a atitude do professor no que diz respeito aos métodos: pedagógicos e disciplinares; as formas de: comunicação, investigação e avaliação; e as técnicas e tecnologias, conforme esquematizamos na figura 1. 
Figura 1: Competências para formação docente em TDIC

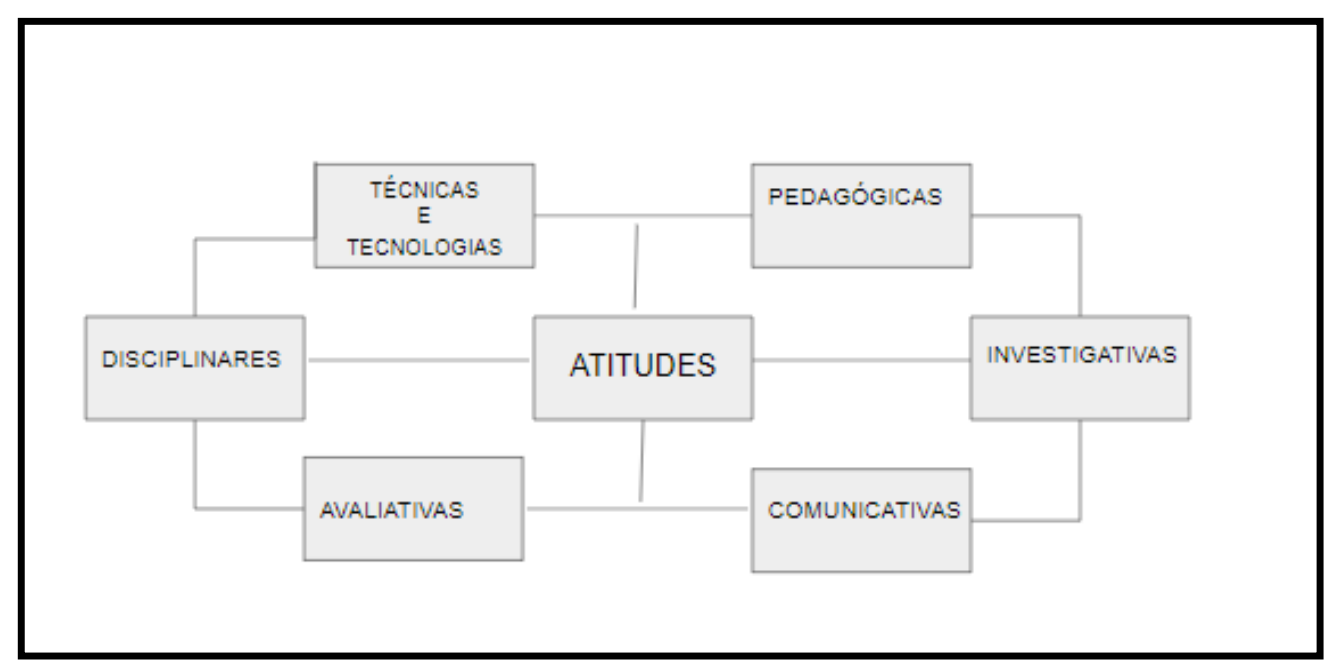

Fonte: adaptado de Márquez et al. (2018)

Frente a essas competências, o ERE causou um efeito devastador nas IES, ora por não estarem preparadas para implementação de Ambientes Virtuais de Aprendizagem (AVA's), algumas até mesmo sem nenhum sistema interno já em funcionamento. Outras que começavam a inserção das TDIC's antes mesmo da pandemia e poucas que já tinham sistemas de ensino híbridos em suas atividades presenciais. Com a suspensão das atividades presenciais, iniciou-se uma corrida, para que os estudantes e o calendário acadêmico das IES não fossem prejudicados. Algumas ferramentas tecnológicas desenvolvidas para o ensino, passaram então a substituir a sala de aula física e os docentes tiveram que instantaneamente passar da lousa para as telas digitais, sem que tivessem ao menos passado por uma formação inicial tecnológica e metodológica.

Moreira, Henrique \& Barros, (2020), relatam que os professores se transformaram em youtubers compulsoriamente, pois passaram a realizar aulas por meio de videoaulas, videoconferências e lives, com aplicativos tais como: Skype, WhatsApp, Google Meet, Zoom, Instagram, entre outros. As salas de aulas foram substituídas por plataformas de aprendizagem como: Moodle, Microsoft Teams e Google Classroom. No entanto, na grande maioria dos casos, não ocorreu a transposição didática para tais tecnologias, sendo uma utilização de forma meramente instrumental, o que além de causar danos a aprendizagem dos estudantes, podem provocar estafa laboral aos docentes.

Muito além também da formação docente, devemos pensar sobre a atitude dos estudantes frente ao uso da TDIC's, as mudanças educacionais, já anunciavam mesmo antes da pandemia, um novo olhar para o processo de aprendizagem. As formas de promover a educação estão inseridas nas novas ações da realidade contemporânea que temos da sociedade bem como o perfil dos novos estudantes, os quais se tornaram produtores de informação e conhecimento e, querem participar e compartilhar constantemente tudo o que estão vivenciando. "Nossos alunos deixaram de ser alunos passivos para serem criativos, muito ativos, criadores ativos" (FEDRIZZI, 2017, p.13). Esse contexto exige que os docentes também sejam mais dinâmicos e atualizados para que possam manter o interesse em suas aulas.

No percurso do tempo a educação passou (e ainda passa) por constantes mudanças que impactam diretamente a forma de pensar, de relacionar e de agir do ser humano, 
sobretudo com a chegada era digital que interfere no contexto coletivo, econômico, político e ainda impulsiona as seguintes competências, apresentadas por Gómez:

Capacidade de utilizar e comunicar de maneira disciplinada, crítica e criativa o conhecimento e as ferramentas simbólicas que a humanidade foi construindo através dos tempos. Capacidade para viver e conviver democraticamente em grupos humanos cada vez mais heterogêneos, na sociedade global. Capacidade de viver a atuar autonomamente e construir o próprio projeto de vida (GÓMEZ, 2015, p. 77).

Na mesma perspectiva, Resnick, Levine \& Tasley (1991) já enfatizavam que na era digital o aprender a aprender requer desenvolver uma mente crítica que envolve enfatizar o sentido, a dimensão ética e responsável sobre o rigor e a orientação da busca e da aplicação; combinar eficiência e sentido; questionar as prioridades e estratégias; avaliar os rendimentos.

Para tanto, integrar o complexo ciberespaço da cultura digital exige do estudante e do professor aprender os meandros da comunicação digital para selecionar, processar, compreender, difundir e compartilhar os significados recriados de forma individual, pelos grupos ou comunidades virtuais heterogêneas.

Dessa forma, a sinergia do trabalho constitutivo dos processos educativos, constituem-se de elementos fundamentais para a formação inicial e continuada dos docentes. Libâneo (1998, p. 136) considera que "[...] se definirmos a ação educativa pelo seu caráter intencional, também a ação docente se caracteriza como direção consciente e intencional do ensino", uma vez que a prática pedagógica reflete e refrata todo processo de aprendizagem dos estudantes que já trazem da vida exterior à escola, conhecimentos prévios e que deveriam ser integrados a essa prática consciente.

\section{TECNOLOGIAS E PRÁTICAS DOCENTES: CONTEXTOS E HABILIDADES}

A ação potencializadora das tecnologias nos últimos 10 anos têm mostrado a importância do (re)pensar as práticas pedagógicas de professores e instituições de ensino que até então eram "ditas tradicionais". A virtualidade das relações de ensino se mostra necessária no contexto de globalização e no processo emancipatório da humanidade.

Uma diversidade de textos contendo severas críticas ao uso das tecnologias em sala de aula são apresentados rotineiramente. Porém, o que se deve levar em consideração é que o uso das TDIC's promove processos emancipatórios e inclusivos a estudantes e professores. Com relação a esses processos, Belloni (2012, p. 29), concebe que a integração das TDIC's aos processos educacionais transcende as questões puramente técnicas para situar no nível da definição das grandes finalidades sociais da educação. Ou seja, os fins e os modos desta integração dependem das escolhas da sociedade.

A emergência do trabalho com as tecnologias nos espaços educativos com a ampliação da pandemia, "forçou" alunos e professores a redesenhar suas formas de conceber o processo de ensino e aprendizagem. Para os docentes, o caminho guiado ou independente pela formação continuada quanto ao uso das TDIC's foi imprescindível. Conforme Godói e Silva,

A formação continuada ocorre quando os professores estão em pleno exercício de sua profissão. Essa modalidade constitui-se com 
atividades planejadas por instituições ou até pelos próprios professores, de modo a permitir o desenvolvimento profissional e aperfeiçoamento do ensino que ministram (GODÓl E SILVA, 2016, p 171.).

Os processos formativos continuados em contexto pandêmico tiveram suas ofertas de certa maneira "facilitadas". Quase todos os dias temos diversas atividades síncronas e assíncronas com os mais renomados especialistas em educação, desenvolvimento humano e gestão do país, promovendo aos docentes um rápido acesso ao contínuo preparo para o uso de ferramentas para suas práticas no ERE.

As novas formas de aprender tencionam as práticas pedagógicas novos olhares metodológicos de ensino (para os docentes) e de aprendizagem (para os discentes). As redes sociais, promoveram nas realidades sociais um novo olhar para o processo educativo e uma nova mudança de posicionamentos em práticas pedagógicas. Para Rojo:

Essa mudança de concepção e de atuação, já prevista nas próprias características da mídia digital e da web, faz com que o computador, o celular e a TV cada vez mais se distanciam de uma máquina de reprodução e se aproximem de máquinas de produção colaborativa [...]. Todas essas ferramentas mais recentes permitem (e exigem, para serem interessantes, mais que a simples interação, a colaboração (ROJO, 2009, p. 24).

A convergência das redes para o processo de aprendizagem tornou-se fundamental na atualidade pandêmica, pois, "[...] a estrutura em rede e o formato/funcionamento hipertextual e hipermidiático facilitam as apropriações e remissões e funcionam [...] por meio da produção, cada vez mais intensa, de híbridos e polifônicos" (ROJO, 2009, p. 25).

O aperfeiçoamento das novas metodologias de aprendizagem, ditas "ativas", que para Fialtro \& Cavalcanti (2018, p. 07) são vistas como "[...] um tipo de inovação incremental que pode ser adotado dentro do circuito escolar-universitário, sem desorganizar a estrutura clássica das instituições de ensino". Assim como as TDIC's, as Metodologias Ativas (MA's) não têm por objetivo descaracterizar o ensino. Pelo contrário, as MA's objetivam um repensar na forma de gestão e desenvolvimento do processo de aprendizagem, pois, preconizam a demanda essencial dos recursos humanos por meio da atuação dos estudantes e professores.

As MA's são fundamentadas, de acordo com Fialtro \& Cavalcanti (2018) pelos princípios do protagonismo dos estudantes, da colaboração e da ação-reflexão, promovendo aos professores o papel de mediadores do processo de aprendizagem. As autoras apresentam em forma de gráfico esses princípios, que trazemos neste texto de maneira adaptada: 
Figura 2: Princípios Essenciais das Metodologias Ativas

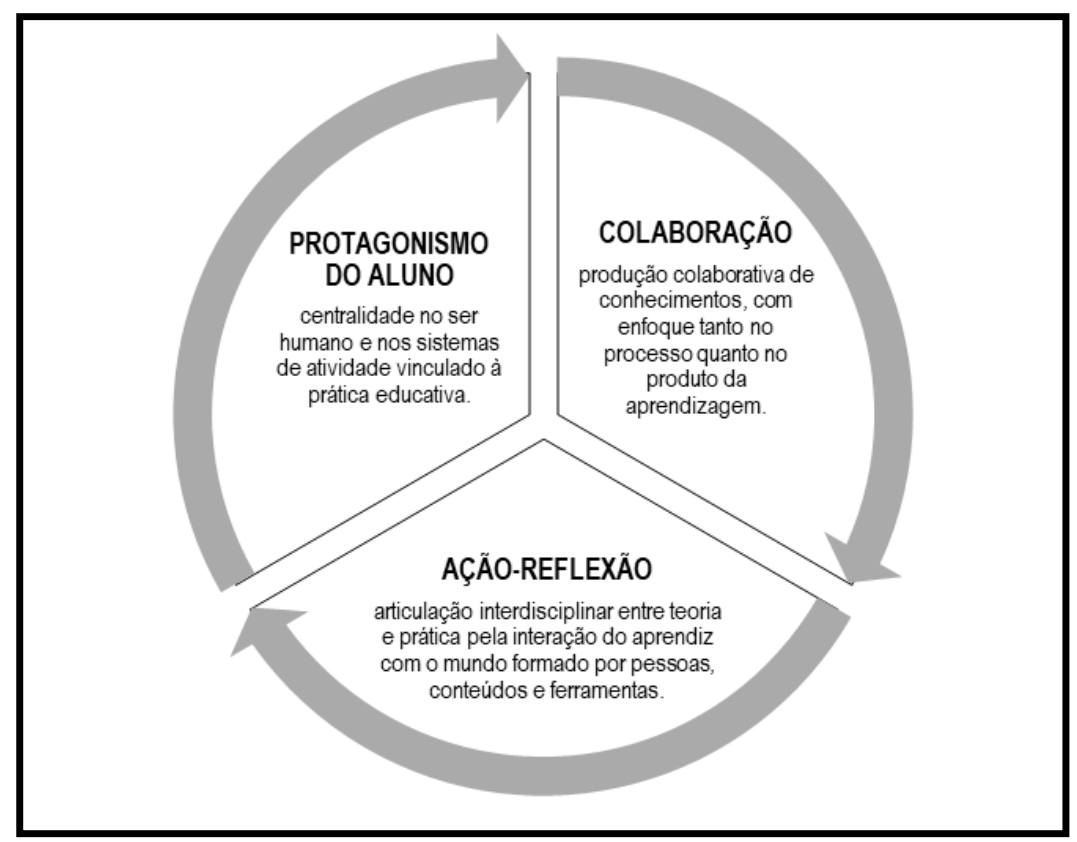

Fonte: Fialtro \& Cavalcanti (2018)

Com o uso das MA's, em contexto de isolamento social, as IES planejam seu retorno com o uso da modalidade híbrida, no qual o ensino ocorre de múltiplas maneiras, de forma contínua em diferentes espaços (BACICH; TANZI NETO \& TREVISANI, 2015).

Dessa forma, com o desenvolvimento do ERE nas escolas e universidades, provoca nos grupos docentes a busca pelas melhores formas de promover o ensino e estimular nos estudantes formas de aprendizagens diversificadas. Nesta nova modalidade, os docentes podem trabalhar três estratégias metodológicas diferentes: o Ensino Híbrido, a Sala de Aula Invertida e as Práticas de Gamificação, uma vez que, estas abordagens organizam níveis de aprendizagem promovendo a autonomia dos estudantes e a interação destes com os docentes. Tais práticas têm potenciais êxitos, principalmente em se tratando de ERE, visto que como os estudantes ainda não estavam adaptados a aprendizagem on-line, estas práticas metodológicas são altamente engajadoras.

Destacamos os conceitos básicos de cada uma delas, sendo:

Ensino Híbrido (EH): Com as adaptações das rotinas das salas de aula, o EH pode ser uma alternativa fundamental para o trabalho pedagógico com turmas que antes do agravamento da COVID-19 eram puramente presenciais, pois, une a realidade cotidiana do ensino presencial com o acréscimo de um ensino on-line que pode ser desenvolvido por meio de plataformas ou Ambientes Virtuais de Aprendizagem (AVA).

Para Camargo \& Daros (2018, p. 62-63) “[...] por meio desses programas, os estudantes e professores têm a possibilidade de se relacionarem, trocando informações e experiências, realizam trabalhos individuais e em grupos, promovem debates e fóruns, entre outras formas de tornar a aprendizagem mais significativa". Nesta abordagem, o trabalho pedagógico síncrono e assíncrono o professor poderá propor momentos de aprendizagem em que os estudantes transcendam os limites de espaço-tempo da aula convencional. 
Sala de Aula Invertida (SAI): Essa abordagem de trabalho tira o professor da centralidade do processo de ensino, possibilitando aos estudantes um trabalho dialógico com vistas a aprendizagem significativa. Valente (2018) menciona que a diferença desse modelo para o tradicional é que, os conteúdos em uma Aula Invertida são estudados previamente. A prática pedagógica em sala é voltada para as discussões e reflexões acerca dos conteúdos apresentados e lidos anteriormente à aula e, a função do professor é trabalhar a dificuldade dos estudantes, a partir da verificação das questões mais complicadas trazidas pelos discentes após a leitura e compreensão do conteúdo.

Para a implantação da abordagem da Sala de Aula Invertida, dois aspectos são fundamentais: "[...] a produção de material para o aluno trabalhar on-line e o planejamento das atividades a serem realizadas na sala de aula presencial" (VALENTE, 2018, p. 31). Quanto aos materiais, o autor menciona que o professor tem uma gama de possibilidades para elaborá-los, mixá-los ou remixá-los podendo utilizar-se das mais diversas ferramentas virtuais.

Gamificação: Filatro \& Cavalcanti (2018) definem a Gamificação como as práticas de inclusão de elementos das regras dos jogos como desafios, níveis, narrativas de fundo, ranqueamento, nos mais diversos contextos de aprendizagem. Para as autoras, a gamificação pode ser classificada em dois tipos:

Gamificação de Conteúdo - aplicação de elementos de jogo para alterar alguns conteúdos e materiais abordados em curso; prevê a criação de narrativas, personagens, situações relacionadas a um desafio maior, explicitado na gamificação.

Gamificação Estrutural - aplicação de elementos de jogo ao processo de aprendizagem para motivar os participantes, oferecendo feedback e emblemas quando eles agem de forma esperada ou prevista (FILATRO; CAVALCANTI, 2018, p. 257, grifos das autoras).

As autoras salientam a importância de compreender a gamificação com algo diferente dos jogos didático-pedagógicos (prontos) que estão disponíveis em lojas e departamentos. A ideia é incorporar a linguagem dos jogos em contextos externos a eles (FILATRO; CAVALCANTI, 2018), no caso, a sala de aula e o processo de ensino e aprendizagem. A prática com essa abordagem desenvolve nos estudantes, segundo Mattar (2013, p. 124) "[...] diversas habilidades buscadas pela educação como comunicação, interação, colaboração e resolução de problemas", uma vez que os novos estudantes estão cada vez mais imersos em práticas colaborativas on-line, permitindo maior adesão e facilidade para novas aprendizagens.

As três abordagens de trabalho pedagógico apresentadas promovem um contato e engajamento assíduo dos estudantes, uma vez que, envoltos na construção do processo de aprendizagem, sentir-se-ão cada vez mais motivados em construir e (re)significar novos e velhos conhecimentos certamente apresentados a eles de maneira tradicional.

Ao professor, conhecer as Metodologias Ativas para construção do processo de ensino e aprendizagem, além de promover atualização funcional promove um trabalho pedagógico mais ativo e leve para si, para os colegas que compartilham tais desafios e sobretudo aos estudantes, receptores na formação acadêmica. 


\section{PERCURSO METODOLÓGICO}

O corpus da pesquisa é composto pela amostra de docentes do ensino superior brasileiro, nas diferentes áreas de conhecimento, que estão realizando o Ensino Remoto Emergencial (ERE), durante a pandemia da COVID-19, mais precisamente com recorte temporal no mês de julho de 2020. Os entrevistados foram contatados por mensagem enviada por meio do correio eletrônico, enviada para suas respectivas caixas de mensagens, a partir da coleta de dados via websites oficiais das IES credenciadas pelo Instituto Nacional de Estudos e Pesquisas Educacionais Anísio Teixeira (INEP). Além disso, os pesquisadores utilizaram também suas redes sociais Whatsapp e Instagram, para o envio de convites para participar da pesquisa.

Foram enviados um total de 1200 links com o questionário. $O$ intervalo de envio e coleta das informações compreendeu de 01 a 25 de julho de 2020. Desse total de enviados, obtivemos retorno de 445 respostas, o que possibilitou uma taxa de retorno de $37 \%$, que confrontado tal resultado com a pesquisa realizada por Dias; Anjos \& Araújo (2019) que utilizaram a pesquisa com o envio de questionários pela internet, cujo resultado foi de $34,8 \%$, obtivemos um retorno acima da média, ou seja satisfatória. Do total de questionários respondidos foram utilizados como análise 442, já que 3 respondentes após a leitura do Termo de Consentimento Livre e esclarecido (TCLE) optaram por não participar.

De acordo com o INEP, com o último censo publicado da educação superior em 2019, referente ao ano anterior, são 384.474 docentes atuando, sendo 173.868 das IES públicas e 210.606 das IES privadas. Considerando os parâmetros de pesquisa estipulados acima, com uma margem de erro de $5 \%$ e de nível confiança de $95 \%$ sobre a população destacada pelo INEP, com uma distribuição homogênea (80/20) constatouse que se fez necessário entrevistarmos o número mínimo de 200 docentes.

O critério utilizado para a estratificação da amostra foi: a) Docentes brasileiros; b) Docentes brasileiros em nível superior; c) Docentes brasileiros que atuam no ensino superior presencial; d) Docentes brasileiros que atuam no ensino superior presencial que aderiram ao Ensino Remoto Emergencial (ERE) durante a pandemia.

Como Instrumento de pesquisa foi utilizado um questionário estruturado elaborado com perguntas fechadas e uma questão aberta utilizando o aplicativo Google Forms, que faz parte do pacote G-Suite, um serviço de armazenamento e sincronização de arquivos.

Uma parte do questionário o respondente pode fazer uma ou mais opções e outra parte do formulário de avaliação, atribuiu menções de 1 a 5 para cada item avaliado conforme uma escala de Likert, que conforme (SPIEGEL,1992) este tipo de escala requer que os entrevistados indiquem seu grau de concordância ou discordância com as declarações relativas à atitude que está sendo medida: 5 - Ótimo 4 - Muito Bom 3 Bom 2 - Regular 1 - Insuficiente.

A intersecção dos dados coletados teve por finalidade fornecer o maior (e melhor) leque possível de informações que subsidiarão as ações de melhoria pedagógica, obtidas, através de um Índice de Satisfação Pessoal (ISP) calculado, utilizando-se a tabela $z$ de uma distribuição normal, o que é justificado estatisticamente pelo Teorema do Limite Central. Para a determinação do valor de $z$, utiliza-se a relação: $z=(\mu-x) / S$, Onde, $\mu$ é a média desejada (neste caso 3), x é a média geral obtida e $s$ é o desvio padrão da amostra. Na tabela z, o valor percentual correspondente ao valor de $z$, é o ISP. 
Uma pergunta com características qualitativas foi realizada para levantar a opinião sobre o aprendizado que o docente pode considerar relevante em sua prática docente no Ensino Remoto Emergencial (ERE), sobretudo nos aspectos didáticos. Salienta-se que todas as perguntas do questionário buscaram valorizar a opinião dos participantes no sentido de analisar a qualidade do ensino oferecido durante o ERE.

O eixo central na análise, orientados pelos preceitos da abordagem qualiquantitativa, que nortearam a elaboração dos questionamentos, que de "os métodos de análise de dados que se traduzem por números podem ser muito úteis na compreensão de diversos problemas educacionais" (GATTI, 2004, p.113). Além disso, a combinação deste tipo de dados com dados oriundos de metodologias qualitativas, podem vir a enriquecer a compreensão de evento, fatos, processos (GATTI, 2004).

Os dados coletados foram analisados a partir do conjunto de respostas dos questionários respondidos, buscando a integração (quanti + quali), de forma mixada, ou seja, estabelecendo uma estratégia de triangulação concomitante por intermétodos, que considera os dados que estavam fundidos, os que se mantiveram separados ou ainda o que estavam de modo combinados (DENZIN, 2009; GUION, 2002).

Dessa forma, a triangulação por intermétodos adotada para nossa discussão, foi baseada na análise das interpretações dos dados quanti-qualitativos que se firmam da seguinte forma: a) abordagem do assunto, predominantemente qualitativa; b) do ponto de vista de seus objetivos, como descritiva e c) com relação aos procedimentos técnicos de forma quantitativa, obtida pelas respostas dos entrevistados, sem desprezar as possíveis interferências qualitativas.

A pesquisa atendeu ainda os aspectos éticos dos estudos, de acordo com Resolução n.510/2016 do CNS e foi aprovada pelo Comitê de Ética da Universidade Estadual de Mato Grosso do Sul, de acordo com o protocolo CAAE: $33114820.1 .0000 .8030 \mathrm{em}$ 09/06/2020.

\section{APRESENTAÇÃO DOS RESULTADOS}

As questões iniciais do instrumento de coleta de dados objetivaram levantar o perfil dos 442 respondentes. Os dados relacionados apontaram que $54,4 \%$ são compostos por mulheres; $29,4 \%$ com faixa etária de 36 a 45 anos e $29,4 \%$ de 50 a 60 anos predominantemente; sobre o tempo de serviço é de 25 anos ou mais e em segundo lugar de 15 a 20 anos; sobre o local de residência os três estados mais representativos foram 38\% Mato Grosso do Sul, 14,3 de São Paulo e 13,8\% do Paraná; sobre o grau de escolaridade $46 \%$ possui doutorado e $19,4 \%$ pós-doutorado; sobre a área de formação acadêmica é predominante em $28,7 \%$ em Humanas e em segundo $26,8 \%$ em Ciências Sociais.

Nesse aspecto percebemos que aos respondentes possuem experiência e formação sólida na atuação do ensino superior, pelo menos atendem as exigências da Lei de Diretrizes e Bases da Educação Brasileira, n 9393/96 (BRASIL, 1996). Apesar disso, cabe considerar o papel dos docentes que "[...] a efetiva prática do professor universitário repousa sobre o tripé que envolve os conhecimentos específicos relacionados à matéria, às habilidades pedagógicas e à sua motivação" (GIL, 2018, p. 13).

Sobre o vínculo profissional $54 \%$ é oriundo de IES pública e $67,6 \%$ atua em universidades; sobre as horas dedicadas de trabalho nas IES $45,1 \%$ possui dedicação 
exclusiva com 40 horas semanais e $22,7 \%$ em Tempo Integral com 40 horas semanais em mais de uma IES.

Verificamos que os docentes possuem contratos de trabalhos que permitem uma dedicação maior com o ensino superior, o que pode elevar inclusive os indicadores de qualidade na dimensão do corpo docente, de acordo com Lei $n^{\circ} 10.861$, de 14 de abril de 2004, que regula o Sistema Nacional de Avaliação da Educação Superior (Sinaes) que tem como principal finalidade assegurar o processo nacional de avaliação das IES.

Sobre as principais rotinas dos docentes durante o atendimento do ensino remoto foi solicitado que cada um apontasse até três opções, destacando-se: $58,7 \%$ tem se dedicado às leituras e o assunto com maior interesse 33,9\% na Educação e 10,8\% sobre Comportamento. Além disso, 54,2\% ficavam conectados à internet, $47,7 \%$ planejamento de aulas e $47,1 \%$ estudando.

Outro aspecto relevante, somados os aspectos na produção de conteúdo virtuais 17,5\%, o uso de aplicativos $20,1 \%$, o envio de mensagens $22,2 \%$, somam $59,8 \%$ do tempo geral dos docentes. Sobre a quantidade de dias dedicados na semana ao planejamento das aulas $29,4 \%$ respondeu 5 dias e $20,1 \% 4$ dias.

Com isso, observamos que a rotina se intensificou, causando um nível de stress saliente. Inclusive foi mensurada a carga de stress e ansiedade desses docentes. Numa escala de 1 (muito baixa) a 5 (muito alta), os docentes atribuíram 33,7\% nível 4 (alta); $17,3 \%$ nível 5 (muito alta) e $29,6 \%$ (média). Somados os níveis 4 e 5 , destacou-se que $51 \%$ dos respondentes. Confrontando com as três principais razões apontadas por eles, $50,4 \%$ alegou que foi por conta do aumento de carga de trabalho com o ensino remoto, $37 \%$ o distanciamento social e $20,8 \%$ falta de participação/engajamento dos estudantes.

No aprofundamento das respostas inerentes às questões pedagógicas com o uso das tecnologias, $64,4 \%$ disseram estar preparados para lidar com o uso das tecnologias em suas aulas e $30,9 \%$ pouco preparado. Desses, apontaram os três principais dispositivos utilizados diariamente, entre eles: $80,1 \%$ via WhatsApp, 67,6\% Aplicativos do Google e $43,8 \%$ aplicativos da Microsoft. No entanto, importante destacar que o uso dos recursos tecnológicos seja eficaz, pois “[...] requer-se dos professores não apenas que identifiquem suas vantagens e limitações, mas também que saibam usá-los com perícia adequada" (GIL, 2018, p. 203).

Buscando uma resposta aos desafios de lidar com o uso das TDIC's, 55,7\% afirmaram receber formação continuada pela IES, em contraponto com os $27 \%$ responderam às vezes/raramente e $17,3 \%$ nunca recebeu qualquer apoio nesse sentido. Como resposta às principais motivações do docente em buscar esse tipo de incentivo institucional $39,5 \%$ justificou como formas de ampliar formas de ensino-aprendizagem, $26,3 \%$ conhecer novas metodologias e $18,1 \%$ atender as demandas da IES.

Nesse sentido, “[...] o professor, ao decidir pela utilização dos recursos tecnológicos no ensino, precisa levar em consideração outros elementos além das ferramentas tecnológicas" (GIL, 2018, p.197) tais como: os objetivos e o conteúdo da disciplina. Além disso, o professor precisa conhecer suas vantagens, limitações e sobretudo os efeitos que a tecnologia pode provocar na aprendizagem (GIL, 2018).

$\mathrm{Na}$ atuação docente durante o ensino remoto, os docentes responderam que $57,2 \%$ desenvolveu uma comunicação síncrona e assíncrona simultaneamente, 30,7\% apenas síncrona e 7,3\% exclusivamente assíncrona. Nesse aspecto observamos que as atribuições docentes foram além dos preceitos do ensino remoto de forma emergencial, ou seja, os professores estão produzindo conteúdos e disponibilizando nos dispositivos institucionais e fora deles para responder às demandas das IES e dos 
estudantes, como já ocorre na EAD, modalidade de ensino que já possui de forma consolidada seu Ambiente Virtual de Aprendizagem (AVA), regulamentada pela Lei Federal $n^{\circ}$ 9.394, de 1996 (BRASIL, 1996) e, posteriormente foi regulamentada pelo Decreto 5.622 de 2005 (BRASIL, 2005).

Questionando como seria possível melhorar o ensino remoto, as três principais respostas foram: $39,7 \%$ acesso ampliado da internet para os estudantes, 36,7\% maior interação das IES com os estudantes, 32,4\% melhoria dos dispositivos oferecidos pela IES aos docentes e estudantes. Verificamos com esses dados que os maiores entraves que dos docentes apontaram extrapolam os limites pedagógicos pois estão associados a necessidade de infraestrutura e acessibilidade necessária que as IES precisam considerar ao tratar o ensino com maior qualidade.

Corroborando, "[...] as crenças dos dirigentes das instituições educacionais nem sempre coincidem com as crenças dos professores. Até mesmo porque nem todos os dirigentes podem ser considerados educadores [...]" (GIL, 2018, p. 14). Além disso, “[...] muitos dirigentes tendem a admitir que basta oferecer recursos mínimos [...] e que o aprendizado se dá naturalmente pela atenção aos estudantes e pelas tradicionais anotações em sala de aula" (GIL, 2018, p. 14).

Como apresentado na metodologia para atender a abordagem qualitativa, o Quadro 1 a seguir traz uma amostra das respostas expressas pelos respondentes apontando os aprendizados que podiam ser considerados relevantes na prática docente no Ensino Remoto Emergencial (ERE).

Quadro 1: Amostra de razões sobre os aprendizados que podiam ser considerados relevantes na sua prática docente no Ensino Remoto Emergencial

\begin{tabular}{|l|l|}
\hline Entrevistados & Respostas \\
\hline E 11 & $\begin{array}{l}\text { “Ampliar a participação dos estudantes no meio remoto; aumentar capacitação dos } \\
\text { professores para o uso da TDIC's; uniformizar o meio de comunicação, ou seja, todos } \\
\text { usando a mesma plataforma. Contudo, isso pode impactar nas dificuldades de acesso } \\
\text { tanto de alunos quanto de professores". }\end{array}$ \\
\hline E 42 & $\begin{array}{l}\text { “É um momento de inovar e buscar se adaptar e buscar ter equilíbrio com tantas } \\
\text { mudanças para passar confiança aos alunos". }\end{array}$ \\
\hline E $\mathbf{8 4}$ & $\begin{array}{l}\text { "O ensino remoto é precário e não pode ser comparado com educação a distância” } \\
\text { "Toda prática de ensino-aprendizagem pode (e deve) ser melhorada, ajustada e } \\
\text { inovada. Vejo como ponto positivo este aspecto causado pela pandemia, } \\
\text { obviamente, excluindo todas as mazelas que ela proporcionou. Entretanto, ficou } \\
\text { evidente que podemos mudar e nos ajustar. Ficou evidente que, embora estejamos } \\
\text { ensinando, tivemos nosso momento de aprendizado com esta nova modalidade de } \\
\text { ensino. Para mim, é inegável o quanto cresci como docente e o quanto vou } \\
\text { proporcionar positivamente nas minhas aulas nos semestres posteriores". }\end{array}$ \\
\hline E 129 & $\begin{array}{l}\text { "Principalmente que precisamos aprender sempre. Quem não se reinventar estará } \\
\text { fora do mercado. Que o ensino e aprendizagem podem ocorrer em qualquer lugar". }\end{array}$ \\
\hline
\end{tabular}


Considerando os depoimentos amostrais, quando superados os limites de infraestrutura tecnológica e de formação continuada durante o ensino remoto, que estão impactados com a inclusão forçada dos dispositivos de TDIC's, aponta-se para uma tendência para o ensino híbrido, ou seja, mesclando as experiências do ensino presencial e a distância.

De acordo com Morán (2015), o ensino híbrido a educação ocorre de forma diferente, com a promoção de atividades e com competências necessárias para a sociedade atual e multicultural. A inovação ocorre tanto o professor quanto o aluno, inclusive de mudança comportamental nas relações sociais. Da mesma forma, "[...] existem muitas vantagens da utilização de recursos tecnológicos no Ensino Superior" (GIL, 2018, p. 191). Entre elas, a aproximação da realidade, facilitação do acesso à informação, criação de um ambiente agradável de aprendizagem, promoção do aprendizado independente e facilitação da avaliação (GIL, 2018).

No entanto, a aprendizagem ativa do aluno com qualidade depende da tecnologia, dos recursos e habilidades dos professores elaboradores e ministradores dos cursos, assim com uma pedagogia compatível (TORI, 2009). Para tanto, conhecer algumas desvantagens ao uso indiscriminado das tecnologias se faz necessário, entre elas a utilização com finalidade exclusiva recreativa para os estudantes; dependência excessiva do recurso pelo professor para ministrar suas aulas; além do incentivo a passividade do estudante durante as aulas síncronas e assíncronas, sem que que haja estímulo pelo professor na participação ativa perguntas ou comentários sobre os conteúdos e temas abordados (GIL, 2018).

\section{CONSIDERAÇÕES FINAIS}

Diante de tais inferências postuladas na pesquisa, podemos salientar a importância das transformações na práxis docente do ensino superior brasileiro, visto que o Ensino Remoto Emergencial, abriu muitos questionamentos frente ao uso das TDIC's na IES. Dentre os desafios postos, a escassez da formação continuada docente é uma realidade muito presente nas IES, com números que somam $44,3 \%$ raras formações ou nenhuma formação.

Com a pressão provocadas pelas IES para atendimento da ERE, os docentes estão buscando diversas formas de interagir com os estudantes, inclusive procurando atender as demandas que vão além da habilidade tecnológica como também emocional, devido ao stress causado pelo acúmulo de atividades, incluindo a produção de conteúdo e resistência ao ensino síncrono e assíncrono e as mudanças para a modalidade de trabalho em home office.

É possível inferir hipoteticamente que a educação superior brasileira passará por uma grande transformação híbrida, entre o analógico e digital, no entanto os professores que não foram capacitados e não receberam a infraestrutura necessária das IES para o uso das tecnologias digitais educacionais estarão com altos níveis de stress ou resistência devido aos aspectos socioemocionais pessoais, dos alunos, dos colegas e das famílias, que envolvem a dinâmica da prática docente.

Destacamos com tal reflexão, que muito além das movimentações das IES para formação docente nas ferramentas tecnológicas e metodológicas de ensino, se faz necessário também a emergente discussão sobre os aspectos socioemocionais dos professores, visto que a sala de aula é um universo de emoções, que já no ensino presencial se apresentavam com inúmeros desafios. 
Mas quando pensamos nas mudanças impostas pelo isolamento social, tais desafios somados às angústias no novo normal, podem afetar consideravelmente a saúde mental dos docentes. Fomentar essas discussões e promover diálogos entre as IES e os docentes é fundamental para que na volta às atividades presenciais, tanto estudantes como educadores possam restabelecer uma nova relação, a qual prevalecerá o sentimento de troca mútua e o verdadeiro sentido do ensino e da aprendizagem.

\section{REFERÊNCIAS}

ANTUNES, F. R.; OLIVEIRA, A. A. P.; APOSTÓLICO, M. R.; PUGGINA, A. C. G, Motivação de alunos de cursos presenciais para o uso de tecnologias digitais em disciplinas online. Revista Gaúcha de Enfermagem, Porto Alegre, v. 41, 2020.

BACICH, L; TANZI NETO, A; TREVISANI, F. M. (orgs.). Ensino híbrido: personalização e tecnologia na educação. Porto Alegre: Penso, 2015.

BELLONI, M. L. O que é mídia-educação. 3. ed. Campinas (SP): Autores Associados, 2012. (Coleção Polêmicas do Nosso Tempo).

BRASIL. Lei n. 9.394, de 20 de dezembro de 1996. Estabelece as diretrizes e bases da Educação Nacional. Brasília: Casa Civil, 1996.

BRASIL. Lei n 13.979, de 06 de fevereiro de 2020. Brasília: Presidência da República, $2020 a$.

BRASIL. Ministério da Educação. Referenciais de qualidade para educação superior a distância. Brasília: MEC/ SEED, 2005.

BRASIL. Ministério da Educação. Portaria MEC nª 343, de 17 março de 2020. Brasília: Ministério da Educação, 2020b.

CAMARGO, F; DAROS, T. A sala de aula inovadora: estratégias pedagógicas para fomentar o aprendizado ativo. Porto Alegre: Penso, 2018.

CHARLOT, B. Da relação com o saber às práticas educativas. São Paulo: Cortez, 2013. (Coleção Docência em Formação, Série Saberes Pedagógicos).

DENZIN, N. The research act: a theoretical introduction to sociological methods. Routledge: London, 2009.

DIAS; A.; ANJOS; V.; ARAÚJO, B. Os princípios FAIR: viabilizando o reuso de dados científicos. Em: Dados científicos: perspectivas e desafios. João Pessoa: Editora UFPB, 2019.

FEDRIZZI, A. et al. As escolas e a sociedade do futuro. In: EDUCAÇÃO 3.0: novas perspectivas para o ensino. São Leopoldo, RS: Unisinos, 2017.

FILATRO, A; CAVALCANTI, C. C. Metodologias inovativas na educação presencial, a distância e corporativa. São Paulo: Saraiva Educação, 2018. 
GATTI, B. A. Estudos quantitativos em educação. Educação e Pesquisa, v. 30, n. 1, p. 1130, jan./abr. 2004.

GIL, A. C. Didática do ensino superior. 2.ed. São Paulo: Atlas, 2018.

GODÓı E SILVA, K. A. de. Processo de formação continuada de professores do ensino superior: significados da escolha e avaliação de materiais didáticos digitais. In: EDUCAÇÃO na Era Digital: entrelaçamentos e aproximações. Curitiba: Editora CRV, 2016.

GÓMEZ, Á. I. P. Educação na Era Digital: a escola educativa. Trad. Marisa Guedes. Porto Alegre: Penso, 2015.

GUION, L. A. Triangulation: establishing the validity of qualitative. 2002.

HOLGES, C. et al. The difference between emergency remote teaching and online learning. EducaseReview, 2020.

LIBÂNEO, J. C. Pedagogia e pedagogos, para que?. São Paulo: Cortez, 1998.

MÁRQUEZ, E. F.; OLIVENCIA, J. J. L.; MENESES, E. L. Competências digitales em docentes de Educación Superior. Revista Digital de Investigación en Docencia Universitaria-RIDU, v. 12, n. 1, 2018.

MASETTO, M. T. (org.). Docência na Universidade. 4. ed. Campinas: Papirus, 2002.

MATTAR, J. Web 2.0 e redes sociais na educação. São Paulo: Artesanato Educacional, 2013.

MORÁN, J. M. Mudando a educação com metodologias ativas. In: CONVERGÊNCIAS midiáticas, educação e cidadania: aproximações jovens. Ponta Grossa, PR: PROEX/ UEPG, 2015. (Coleção Mídias Contemporâneas, v. 2).

MOREIRA, J. A. M.; HENRIQUES, S.; BARROS, D. Transitando de um ensino remoto emergencial para uma educação digital em rede, em tempos de pandemia. Dialogia, $\mathrm{n}$. 34, p. 351-364, jan./abr. 2020.

OLIVEIRA, R. S. N.; FERREIRA, A. R.; FRANCISCO, D. J. Práticas de letramento digital no ensino superior: implicações na formação inicial de professores. Debates em Educação, v. 12, n. 26, jan./abr. 2020.

ORGANIZAÇÃO DAS NAÇÕES UNIDAS PARA A EDUCAÇÃO, A CIÊNCIA E A CULTURA UNESCO. Metade dos alunos fora da escola não tem computador em casa. 2020.

RESNICK. L. B.; LEVINE, J. M.; TASLEY, S. D. Perspectives on social shared cognition. Washington: APA, 1991.

ROJO, R. Pedagogia dos multiletramentos: diversidade cultural e de linguagens na escola. In: MULTILETRAMENTOS na escola. São Paulo: Parábola, 2009. (Coleção Estratégias de Ensino).

SPIEGEL, M. R. Manual de fórmulas, métodos e tabelas de matemática. São Paulo: Schaum McGraw-Hill, 1992. 
SUGUIMOTO, H. H.; ROLIM, A. T.; MAZZAFERA, B. L.; MOURA, F. A. A. F. Avaliação do letramento digital de alunos ingressantes do ensino superior: uma abordagem exploratória do conhecimento computacional, comunicacional e informacional. Revista Brasileira de Estudos Pedagógicos, v. 98, n. 250, p. 805-821, set/dez. 2017.

TORI, R. F. Cursos híbridos ou blended learning. In: EDUCAÇÃO a distância: o estado da arte. São Paulo: Pearson Education do Brasil, 2009. V.1.

VALENTE, J. A. A sala de aula invertida e a possibilidade do ensino personalizado: uma experiência com a Graduação em Midialogia. In: METODOLOGIAS ativas para uma educação inovadora: uma abordagem teórico-prática. Porto Alegre: Penso, 2018. 